\title{
THE GENOMIC RELATIONSHIP OF SENECIO SQUALIDUS L. AND SENECIO VULGARIS L. AND THE SIGNIFICANCE OF GENOMIC BALANCE IN THEIR HYBRID S. $\times$ BAXTERI DRUCE
}

\author{
RUTH INGRAM \\ Department of Botony, University of St Andrews, St Andrews, Fife, Scotland
}

Received 10.x.77

\section{Summary}

The genomic relationship of $S$. squalidus $\mathrm{L}$. and $S$. vulgaris $\mathrm{L}$. is clarified by a cytological study of the offspring of the F1 hybrid between them. It is demonstrated that the effective gametes produced by the hybrid are all genomically balanced. The importance of this gametic selection in introgression is discussed.

\section{Introduction}

Considerable interest has been aroused in recent years by the accumulating evidence that, in Britain, introgression is occurring between $S$. squalidus L. and S. vulgaris L. (Crisp, 1972; Hull, 1974 $a$ and $b$, 1975; Richards, 1975). Here I report a cytological investigation of the offspring of the Fl hybrid between these two species $(S . \times$ baxteri), in an attempt to clarify the relationship between them. $S$. squalidus is a self-incompatible diploid species $(2 n=20)$ whereas $S$. vulgaris is a self-compatible tetraploid species $(2 n=40)$. $S . \times$ baxteri is triploid $(2 n=30)$. This hybrid was synthesised in 1976 (Ingram, 1977). At first it appeared to be completely sterile, but a low fertility was revealed in 1977 .

\section{Materials AND methods}

The formation of the hybrid $S$. squalidus L. $\times S$. vulgaris L.f. radiatus Hegi has been described in a previous paper (Ingram, 1977).

Preparations of meiosis were obtained from buds fixed in $6: 3: 2$ ethanol : chloroform : propionic acid, and then squashed in lactopropionic orcein.

Staining was not intense, and photographs were therefore taken using phase contrast.

Emasculation technique was the same as that previously used (Ingram, 1977).

\section{HYBRID OFFSPRING}

\section{(i) Backcross progeny}

The backcross $S$. vulgaris $f$. radiatus $\times$ hybrid using the hybrid as the male parent was accomplished without difficulty following emasculation. A total of eight backcross progeny were raised and all were remarkably uniform in morphology. They showed an increase in vegetative vigour compared to the hybrid, but floral morphology was not affected by this overall increase in size. When the hybrid was used as the female parent the backcross 
was unsuccessful. Attempts to backcross the hybrid to $S$. squalidus have also been unsuccessful.

Chromosome numbers in the backcross varied from 40-44. Bivalents predominated at meiosis, though occasional univalents and multivalents were seen in the 42 and 44 classes (plate 1).

The interesting point is that there was a remarkable return to fertility in this group of progeny. The plants were self-fertile, and seed set was high, varying from 30 per cent to 55 per cent of the total florets of the capitulum.

The best explanation seems to be that the functional gametes of the hybrid are those in which all univalents are included in a single nucleus at metaphase 1 , thus producing gametes with 20 chromosomes which are homologous with those of $S$. vulgaris.

\section{(ii) Progeny of deliberate selfing of the hybrid}

One seed was obtained by the deliberate selfing of the hybrid with a large quantity of pollen from other capitula, but without emasculation. The plant was unlike any other individual seen in the course of the investigation. Leaf lobes were narrow and auricles were completely absent. The ligules of the ray florets were longer than usual.

Cytologically, the plant had 22 chromosomes, 20 of which associated in pairs at meiosis, though the meiotic configuration is difficult to interpret and it is suspected that the associations are not true bivalents (plate 1). Further cytological investigations are now being carried out.

This approximately diploid plant could have originated in one of two ways: (1) it could be a polyhaploid, produced by parthogenesis from an egg cell with 22 chromosomes, i.e. an approximately diploid gamete; (2) it could be the result of fusion between two gametes from which most or all of the univalents had been excluded. There is not at the moment sufficient evidence to decide between these alternatives. It is reasonable to assume that if gametes with all the univalents present can occur then gametes with all univalents absent should also occur. On the other hand no evidence for the functioning of haploid gametes was obtained.

\section{(iii) Spontaneous offspring of the F1 hybrid}

Eleven plants were obtained which were spontaneous offspring of five of the Fl hybrids.

One of these plants had 60 chromosomes, presumably resulting from the fusion of unreduced gametes. It is of major interest that in this allohexaploid pairing was regular and fertility high, about 50 per cent of the total florets of each capitulum setting seed. The plant was found to be self-fertile.

The other 10 spontaneous offspring were either approximately tetraploid or approximately pentaploid. Their origin is uncertain, but they must have arisen from female gametes which were either unreduced, or approximately diploid.

\section{Discussion}

It would appear from the data that the genomic complement of $S$. vulgaris $L$. can be represented as $\mathrm{S}_{\mathbf{1}} \mathrm{S}_{\mathbf{1}} \mathrm{VV}$. The genome of $S$. squalidus $\mathrm{L}$. is related to the $S_{1}$ genome, so that when the two are combined in the 
hybrid, regular pairing and separation can occur. It is therefore proposed that the genomic complement of $S$. squalidus $L$. should be represented $\mathrm{S}_{2} \mathrm{~S}_{2}$ and the genomic complement of the hybrid $S . \times$ baxteri Druce as $\mathrm{S}_{1} \mathrm{~S}_{2} \mathrm{~V}$.

The two $\mathrm{S}$ genomes are not considered to be completely homologous, because when the triploid complement of the hybrid is doubled to give $\mathrm{S}_{1} \mathrm{~S}_{1} \mathrm{~S}_{2} \mathrm{~S}_{2} \mathrm{VV}$, there is regular pairing immediately, indicating that the pairing of true homologues has overcome the homoeologous pairing in the triploid. Nevertheless, the $\mathrm{S}$ genomes are sufficiently closely related for gene exchange to occur in the production of the hybrid gametes.

The chromosome numbers of the offspring produced by $S . \times$ baxteri indicate that the effective gametes must all have been approximately $2 x$ or $3 x$. Even the anomalous individual with 22 chromosomes comes into the $2 x$ category if it is interpreted as a polyhaploid. $2 x$ gametes will arise by the inclusion of the whole $\mathrm{V}$ genome in a gametic cell which has undergone regular meiosis for the $\mathrm{S}$ genome, so that the genomic constitution of these diploid gametes is $\mathrm{S}_{1 \times 2} \mathrm{~V}$, where $\mathrm{S}_{1 \times 2}$ is recombinant between $\mathrm{S}_{1}$ and $S_{2}$. $3 x$ gametes will arise by non-reduction.

Only $2 x$ gametes functioned in the production of the 8 plants obtained from the backcross, and a balanced genomic complement was thus restored. Fertility showed a dramatic increase. Since the V genome is inherited unchanged throughout the hybridisation, it is likely to have a buffering effect on disturbance due to recombination between the $\mathrm{S}$ genomes, thus permitting introgression to proceed more rapidly because hybrid effects will be cryptic.

The effects of selection of genomically balanced gametes in triploid hybrids are thus twofold.

(1) The fertility of the backcross is dramatically increased due to immediate return to cytological stability at the tetraploid level.

(2) Introgression is made more probable because one full genome is inherited unaltered, and this will mask the effect of recombination in the associated genome, which would be likely to result in illadapted genotypes.

The importance of introgression between ploidy levels via the selection of genomically balanced gametes has been particularly well investigated in the wheats (Vardi and Zohary, 1967; Vardi, 1970, 1974) but there is evidence that it occurs in other genera too. Dewey (1970) postulated a similar system in his investigation of the hybrid origin of Agropyron albicans Scribn. and Smith, and Ladizynsky and Zohary (1968) demonstrated such selection in Avena hybrids.

In Senecio, Crisp (1972) investigated the offspring of the triploid hybrid $S . \times$ londinensis Lousley (S. squalidus L. $\times S$. viscosus L.). He noted that the functional gametes were always approximately $x, 2 x$ or $3 x$, i.e. always genomically balanced, but he failed to produce a backcross. This could well have been due to a failure in experimental technique, and it seems possible that the potential for introgression between $S$. squalidus and $S$. vulgaris would also exist between $S$. squalidus and $S$. viscosus.

S. $\times$ baxteri and $S . \times$ londinensis are the only triploid hybrids of Senecio, which have been investigated in detail, but from the results, and those of Crisp (1972), the same type of chromosomal balance occurs in the gametes of each of them, and such a balancing system could be widespread in the genus. 
Acknowledgments.-My thanks are due to Mr Sinclair Murray for technical help and to Mrs Gina Wilson for typing the manuscript. I am also grateful to Dr R. J. Abbott for his interest, encouragement and constructive criticism.

\section{REFERENCES}

CRISP, P. C. 1972. Cytotaxonomic studies in the section Annui of Senecio. Ph.D. Thesis, University of London.

DEWEY, D. R. 1970. The origin of Agropyron albicans Scribn. and Smith. Amer. F. Bot., 57, 12-18.

HULL, P. 1974a. Self-fertilisation and the distribution of the radiate from of S. vulgaris L. in Central Scotland. Watsonia, 10, 69-75.

HULL, P. 1974b. Differences in esterase distribution detected by electrophoresis as evidence for continuing inter-specific hybridisation in the genus Senecio. Ann. Bot. N.S., 38, $697-700$.

HULL, P. 1975. Selection and hybridisation as possible causes of changes in the frequency of alleles controlling capitulum-type in Senecio vulgaris L. Watsonia, 10, 395-402.

INGRAM, R. 1977. Synthesis of the hybrid Senecio squalidus L. $\times$ S. vulgaris L. f. radiatus Hegi. Heredity, 39, 171-173.

LADIZINSKY, G., AND ZOHARY, D. 1968. Genetic relationships between diploids and tetraploids in series Eubarbatae of Avena. Canad. Fourn. Genet. Cytol., 10, 68-81.

RICHARDS, A. J. 1975. The inheritance and behaviour of the rayed gene complex in Senecio vulgaris. Heredity, 34, 95-104.

VARDI, A. 1970. Introgression from diploid Aegilops speltoides to tetraploid Durum wheat. Heredity, 25, 85-91.

VARDI, A. 1974. Introgression from tetraploid Durum wheat to diploid Aegilops longissima and $A$. speltoides. Heredity, 32, 171-181.

VARDI, A., AND ZOHARY, D. 1967. Introgression in wheat via triploid hybrids. Heredity, 22, 541-560. 

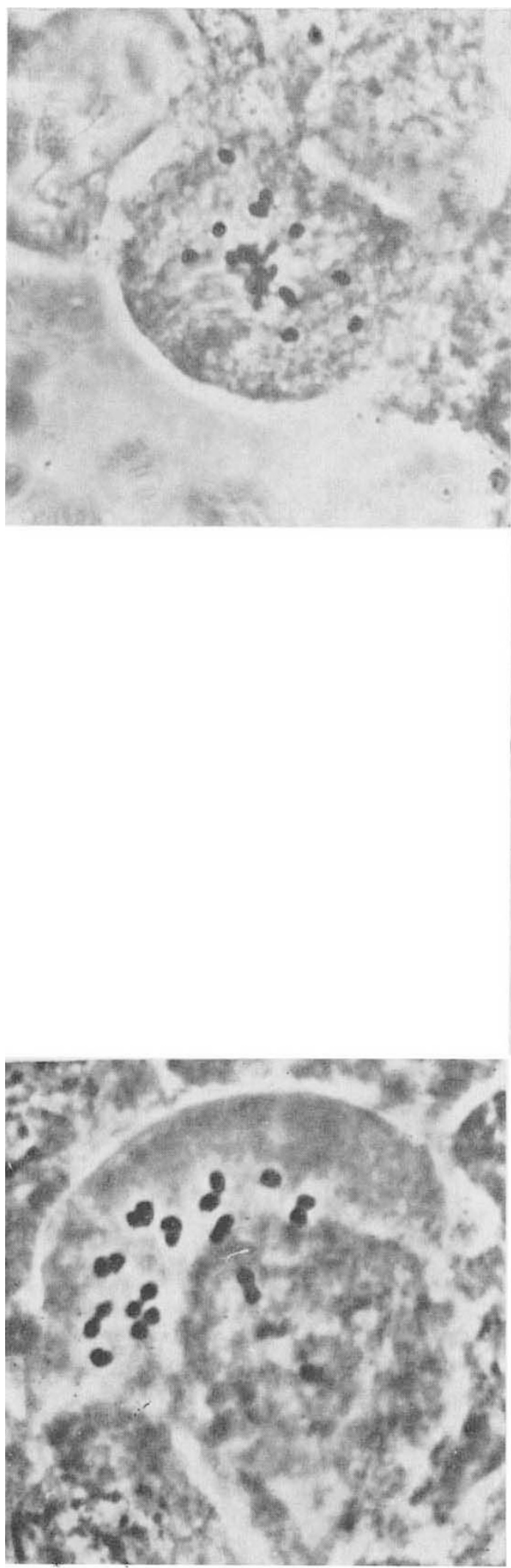

PLATE 1.-Upper: Chromosomes of $S . \times$ baxteri, showing the 10 univalents scattered at meiosis $1(2 n=30)$. Middle: Chromosomes of backcross $S$. vulgaris $\mathrm{f}$. radiatus $\times S$. baxteri $(2 n=40)$. Lower: Approximately diploid offspring of $S . \times$ baxteri showing association in pairs of 20 of the chromosomes $(2 n=22)$. 